Revista Iberoamericana, Vol. LXXVI, Núm. 232-233, Julio-Diciembre 2010, 741-756

\title{
LAS HUELLAS DEL PASADO: INFANCIA Y NARRATIVA SOBRE EL PERONISMO
}

POR

María José Punte

Es en el plano del ensueño, y no en el plano de los hechos donde la infancia sigue en nosotros viva y poéticamente útil.

La poética del espacio, Gastón Bachelard

Hay un cuadro de Daniel Santoro en el que se produce una coincidencia inquietante de temporalidades. Nos referimos a "Hallazgo" (2006) que pertenece a la serie de La leyenda del descamisado gigante. ${ }^{1}$ Allí vemos un paisaje que parece lunar por su fuerte carácter desértico y la ausencia de colores. El hemisferio izquierdo del cuadro está ocupado en su casi totalidad por una figura colosal que monopoliza el foco de atención. Se trata de una cabeza de lo que fuera una estatua de Eva Perón. ${ }^{2}$ Aparece un poco ladeada y con el rostro en semipenumbra. En el hemisferio derecho percibimos a dos niñas, que representan uno de los tópicos de la pintura de Santoro, el de la mamá de Juanito Laguna. ${ }^{3}$ Las dos están vestidas con delantales blancos y se acercan con curiosidad a inspeccionar al otro objeto inerte. En el rincón inferior derecho se ve una versión en miniatura del edificio de la Confederación General del Trabajo (CGT). Y luego sólo hay piedras dispersas sobre el terreno. Los colores son opacos y la única luminosidad proviene de los delantales blancos. Para un imaginario moldeado en los años setenta, esta escena remite al final de la película El planeta de los simios, ${ }^{4}$ momento en el que se produce una anagnórisis que es clave para comprender el tema central de

1 La serie fue expuesta en la Galería Palatina del 15 de noviembre al 4 de diciembre de 2006.

2 La estatua que ahora sobrevive sin cabeza, era parte de un grupo escultórico pensado para ornamentar el frente de la Fundación Eva Perón. Se encuentra actualmente en la quinta-museo de San Vicente, provincia de Buenos Aires (Argentina), actual mausoleo de Juan Domingo Perón.

3 Para acceder a una interpretación sobre éste y otros tópicos de su obra y a la obra misma, nada mejor que la página de Santoro, www.danielsantoro.com.ar. Allí puede verse también el cuadro mencionado.

4 La película Planet of the Apes, estrenada en Nueva York en febrero de 1968, fue dirigida por Franklin J. Schaffner y el rol principal estaba a cargo de Charlton Heston. 
esta distopía. Los personajes no están en otro planeta sino en el planeta tierra, pero en un tiempo futuro. En ese futuro, en el que ya no existe una humanidad tal y como la conocemos, sino lo que parecería ser una civilización regresiva, porque los que gobiernan son monos. El cuadro de Santoro apunta a este otro relato en el que se trabaja sobre las temporalidades para rebatir una concepción progresiva de la historia como la entendida por el positivismo cientificista que dio a luz la teoría de la evolución de las especies. Esa lectura se hace en clave peronista. La cabeza de una estatua gigante de Eva Perón nos estaría hablando de un estadio civilizatorio anterior y exterminado. Son las huellas de un pasado del cual sólo quedan restos desperdigados, cuyo sentido se hace necesario reconstruir. El pasado sólo existe en esos restos que han perdido su disposición como parte de una configuración mayor. El presente es una meseta de límites imprecisos, en donde las proporciones son otras. Los sujetos, inmersos en esa meseta, no parecen estar capacitados para establecer los parámetros que rigen las leyes de la perspectiva. Nos plantea el interrogante de cómo narrar eso que parece precisar de una reconstrucción arqueológica, que quedó enterrado a años luz de esto que consideramos el presente.

La permanente remisión de la obra de Santoro a la temporalidad no es arbitraria sino que se refiere a lo que consideramos un ideologema del discurso justicialista, y que puede resumirse en la dicotomía del antes/ahora. Este esquema de opuestos se instituye sobre una concepción que privilegia el eje temporal por sobre otras categorías. Busca posicionarse como una manera de superar la antítesis de civilización/barbarie, de la cual se había apropiado el discurso opositor al peronismo. Esta otra dicotomía tenía el acento puesto en un eje espacial (ciudad/campo), aunque compartía con aquella la misma concepción progresiva de la historia. El discurso peronista pretendía dar legitimidad a sus políticas en base a esta idea de un progreso que podía ser constatado materialmente en un avance del cual daba testimonio el tiempo. El pasado solía ser descrito con tonalidades oscuras y tenebrosas. El presente era una actualidad luminosa de prosperidad, sobre todo para las clases trabajadoras. Apelaba a una visión de la sociedad que no se presentaba ni como estática ni como estamental, sino caracterizada por la movilidad social y la posibilidad del mejoramiento económico. Pero también buscaba hacerse eco de una modernización que existía como fenómeno global y que surgía como panacea luego de la experiencia traumática de la Segunda Guerra Mundial. Los tiempos estaban tomando otro ritmo como consecuencia del desarrollo técnico, la aparición de los medios masivos de comunicación y el creciente protagonismo de las masas.

El crítico Ernesto Goldar hace notar que la dicotomía del antes/ahora se encontraba sobre todo plasmada en los textos periodísticos que daban cuenta de la experiencia abierta por el peronismo (Goldar 150-153). Quedó fijado en las breves parábolas de la publicación Mundo Peronista mediante las que se buscaba esclarecer a los trabajadores acerca del cambio que suponía esta Nueva Argentina. Otro ejemplo era el programa radial deEnrique Santos Discépolo, quien en sus Charlas de Mordisquito hacía propaganda para el régimen mediante el diálogo mordaz entablado con una impostada voz opositora. La

$$
\begin{aligned}
& \text { Revista Iberoamericana, Vol. LXXVI, Núms. 232-233 Julio-Diciembre 2010, } 741-756 \\
& \text { ISSN 2154-4794 (Electrónico) }
\end{aligned}
$$


cuestión de la temporalidad se encontraba también anudada al binomio olvido/recuerdo. Tomaba cuerpo en el relato discepoliano por medio de permanentes interpelaciones del tipo de “¿Lo grabaste en tu memoria?” o “¿Te acordás?” (Mayer 29-32). Mediante este segundo juego de oposiciones se estaba delineando el espacio de lo que competía a una configuración novedosa del Estado y de sus intervenciones en el campo de lo social. La raya que trazaba una diferencia era la de un Estado que ahora se acordaba de todos aquellos que habían quedado olvidados por el sistema anterior. No se trataba de un discurso fundacional en el sentido de que no provocaba un desplazamiento total del proyecto de un Estado fundado por la tradición liberal republicana. Pero pretendía dar una vuelta de tuerca hacia un nuevo tipo de Estado al que se puede llamar "maternal", y que encontrará su encarnación suprema en la figura de Eva Perón. Daniel Santoro trabaja en su obra pictórica de manera explícita sobre esta doble valencia o Estado bifronte que representó el peronismo durante los diez primeros años de su actuación. En el prólogo a su libro Manual del niño peronista habla sobre la figura de Eva Perón como una "especie de arquetipo que sería como la madre Estado" (Santoro 10). Esa "madre Estado”, según palabras de Santoro, se contrapondría al Estado paternalista que resultó del Estado liberal. El Estado maternal es un Estado sensible que restituye la justicia social. Susana Rosano toma como punto de partida estas reflexiones de Santoro para referirse a una torsión de género que introduce la figura de Eva Perón en la lógica del populismo (Rosano, "El paraíso perdido del peronismo"). A través suyo, dice Rosano, se produce la articulación de un nuevo sujeto nacional y popular y su integración a la performance de la Nación, que logra de ese modo ampliar su base social:

Por un lado, la rearticulación entre género, populismo y modernidad que moviliza su figura tiene consecuencias en el ámbito de la cultura política, a partir de la consolidación de nuevas lógicas en la relación entre espacio público y privado; en la inscripción de la mujer como ícono estético en la producción nacionalista y en la reformulación del Estado como un espacio intersectado por dinámicas populares.

El tema de la construcción política del cuerpo de Eva Perón ha sido laboriosamente trabajado desde diversos enfoques y puntos de vista, entre ellos el de la mencionada Susana Rosano. En su artículo "Reina, santa, fantasma” la autora sigue este triple periplo para categorizar las transformaciones simbólicas a las que quedó sujeto el cuerpo material de Evita. Esto implica la comprensión del cuerpo en tanto que entidad construida no sólo cultural sino socialmente: "El cuerpo, entonces, como construcción simbólica, es una ficción que está siempre inserta en una trama de sentido” (Rosano 190). La verdadera fuente del poder de Eva, afirma Rosano, estaría en ese ejercicio exacerbado de la maternidad simbólica y espiritual que surge como consecuencia sobre todo de su temprana muerte a causa de la enfermedad y del consiguiente esfuerzo del régimen político por mantener la cohesión social mediante el recurso a su santificación.

\footnotetext{
Revista Iberoamericana, Vol. LXXVI, Núms. 232-233 Julio-Diciembre 2010, $741-756$
ISSN 0034-9631 (Impreso)
} 
La imagen de madre nutricia que se descorporiza para convertirse en proveedora de todo lo vital y necesario para su pueblo, serviría a la intención de evitar la dislocación provocada por la descomposición de ese cuerpo, resultante del cáncer. Las etapas de las diversas transformaciones analizadas por Rosano corroboran su tesis de que el cuerpo de Eva, en tanto que imagen privilegiada del régimen, logró conferirle al peronismo una gran visibilidad política y, por lo tanto, operó como fuente de su eficacia simbólica.

El personaje de Evita ha resultado en gran medida atrayente para la crítica por su carácter de mito, por lo tanto de vacío al que es posible llenar de diversos y múltiples sentidos (Ortiga Caicedo 175). Pero también porque su figura pone en evidencia aquello que hay de "performativo" en el género. Para actuar en política, Eva tuvo que pasar por una serie de transformaciones que no poco tenían que ver con rearticulaciones de género, y en cierta medida, con dinámicas de travestismo. De ahí que generara tantas lecturas acerca de su identidad de género ante los conflictos generados entre las "normas de inteligibilidad" a las que se refiere Judith Butler (Butler 71) y los despliegues de esos diversos aspectos identitarios a lo largo de su actuación en el campo social. Es sabido que el cuerpo de Eva Perón se convirtió en un campo de batalla por razones políticas y fue utilizado de modo explícito con el fin de tramar estrategias tanto simbólicas como lisa y llanamente pragmáticas. Pero también porque su presencia tendió a desestabilizar las "relaciones de coherencia y continuidad" que Butler ve como reguladoras de las relaciones entre sexo y género, práctica sexual y deseo. El peronismo dedicó gran parte de su esfuerzo propagandístico en rellenar la sutura que la misma Eva había provocado al desarticular lo que las normas establecían y la funcionalidad de su rol político, en una estructura estatal que se pretendía novedosa.

En ese contexto de un Estado del cual se recuperaba un perfil olvidado, van a resaltar determinados aspectos de una actuación que no por casualidad tenía como destinatario a la infancia. La niñez adquirió una centralidad discursiva enorme para la iconografía peronista, en parte porque constituía el complemento naturalizado de una concepción maternal de la acción política. También porque cuajaba dentro de la configuración de un tiempo que quería despegarse del pasado. De ahí que surgiera un slogan como "Los únicos privilegiados son los niños”. El mundo de la infancia fue por cierto un espacio privilegiado y de eso dan cuenta numerosas obras del período que dejaron fuertes huellas en diversos imaginarios, incluso contrapuestos. No sólo las construcciones edilicias más originales del peronismo tuvieron que ver con el universo infantil, ${ }^{5}$ sino también algunas de las políticas más exitosas como las de salud y educación (Rein). En general muchas de ellas se encontraron ligadas a la Fundación Eva Perón, que como bien definió Plotkin en su libro Mañana es San Perón, se erigió en el "brazo largo” del régimen peronista.

5 Nos referimos a La República de los Niños que aún existe en La Plata y la Ciudad Infantil en el barrio de Núñez, destruida luego de 1955.

$\begin{array}{lllll}\text { ISSN 0034-9631 (Impreso) } & & \text { ISSN 2154-4794 (Electrónico) }\end{array}$ 
Según este autor, se constituía así en sustituto del sistema social que urgía crear para paliar un vacío que el sistema formal no alcanzaba a cubrir. Parte de las fantasías que el peronismo generó en relación con la infancia pueden ser rastreadas en un volumen que reúne una serie de cuentos, a la manera de los libros infantiles tradicionales. Se trata de Hada Buena Argentina, un conjunto de breves relatos cuyo fin era exponer las obras de la Fundación Eva Perón (FEP) para los ciudadanos del futuro. El libro tiene fecha de publicación aproximada de 1950 y no se especifica quién o quiénes fueron sus redactores porque aparece bajo el nombre de su ilustradora, Perla Heim. Escrito con evidente propósito de propaganda, logra insertar la temática política en un universo codificado dentro de los parámetros de la literatura tradicional para niños. Mediante una serie de doce historias se realiza un paneo por las obras de la Fundación. Cada una es un caso paradigmático e individual, que junto con las demás logra dar una visión del conjunto. El efecto primero de fragmentación que propone esta estructura se diluye en la medida en que todo apunta a un referente central que es la Fundación. A su vez, se percibe como omnipresente la figura de Eva Perón, el "Hada Buena” del título, que funciona como metonimia de la institución creada por ella. Evita aparece en cada caso como una madre protectora.

Las doce historias exhiben un panorama sintético pero abarcador de todos los campos en los que operó la Fundación. Eran los terrenos que no tenían cobertura en el sistema institucional: las pensiones por viudez o jubilación, el Hogar de la empleada, los Hogares de Tránsito, la Ciudad infantil, la ayuda médica que llega a todos los rincones del país. Incluso aparece la asistencia internacional en el ejemplo de la Italia devastada de posguerra. La temática del contraste entre el antes y el ahora (el ayer y el hoy) es la constante que atraviesa todos los cuentos como un hilo conductor, y se encuentra asociada a las imágenes de oscuridad y luz. Si bien los cuentos fueron escritos con la intención de publicitar cada una de las obras de la Fundación, resulta interesante ver la manera en que interpelan al universo de temores y de fantasías infantiles. A su vez es llamativo el deseo de evitar toda conflictividad, porque no aparecen resaltadas las oposiciones entre el bien y el mal, que en los cuentos tradicionales suelen ser personificadas por personajes opositores o benefactores. No hay arquetipos antagónicos sino dos realidades opuestas: la carencia, fruto de una situación de injusticia social y la reivindicación mediante Eva Perón y su “brazo largo”, la Fundación. La única dicotomía presente, por lo tanto, es la del vector temporal antes/ahora. A través de este enfrentamiento agonístico, el peronismo buscaba reemplazar otros sistemas de oposiciones para legitimar su obra y estilo de gobierno. Y así conferirle un aura de novedad a su propuesta política. En definitiva eran historias ejemplares de virtudes tales como solidaridad, generosidad y disciplina. Sobre todo tendían a reforzar la idea de que los "milagros" no pertenecían por necesidad a una esfera de lo irrealizable, sino que podían llegar a ser un proyecto para el presente.

Revista Iberoamericana, Vol. LXXVI, Núms. 232-233 Julio-Diciembre 2010, $741-756$
ISSN 0034-9631 (Impreso) 
RELATOS DE INFANCIA: EN BUSCA DEL PARAíSO PERDIDO

Hacer una reconstrucción de ese período implica tener que reconocer la imposibilidad de recrear una serie de elementos que están hechos de una materia inasible, pero por otro lado, actúan de forma persistente sobre los imaginarios. Es decir, existen y son inseparables de ese relato. El primer peronismo lo sospechaba y por eso trabajó en un modelo educativo. Su obra quedó en parte trunca, aunque hay indicios de que la impresión dejada por algunas de esas iniciativas fue tan intensa que permaneció. Muchas de ellas forman parte de un anecdotario de los hogares argentinos, frente a los que sigue siendo pertinente la pregunta sobre el sentido de cada una de esas narraciones. El tema de los libros de lectura redactados por el peronismo puede ser un buen ejemplo. Si bien fueron publicaciones que no tuvieron una mayor trascendencia temporal (aparecieron en $1951 \mathrm{y}$ dejaron de circular en 1955), dejaron un recuerdo imborrable en la memoria antiperonista, que todavía sigue denostándolas por lo que se veía como una intromisión inaceptable del Estado. En ese juicio no se suelen tener en cuenta los aspectos modernizadores de estos libros, desde los que se intentó reflejar una sociedad en pleno cambio y a la que había que interpretar mediante nuevos paradigmas (Wainerman/ Heredia, Plotkin). Las transformaciones provocadas por el peronismo en los imaginarios simbólicos van a empezar a percibirse después. La literatura dejará constancia de estas evoluciones un cierto tiempo más tarde, a partir de los años sesenta (Avellaneda, El habla). El impacto ideológico que recibió el imaginario infantil puede ser rastreado en la obra de esos niños devenidos adultos, pero también en generaciones posteriores. En el tratamiento que se le da al tema de la infancia en la narrativa, se encuentra presente el ideologema mediante el cual el peronismo buscaba fijar su experiencia política, la dicotomía temporal de antes/ ahora. Sólo que en el presente de la narración habrá un giro valorativo en la apreciación de esos tiempos. El ahora luminoso de los años cuarenta será identificado en el futuro con un paraíso perdido, es decir, ese espacio de la infancia al que la memoria retorna como fuente y como refugio.

Podemos ver dos obras que trabajan este asunto. La primera de ellas es la novela Proyección en $8 \mathrm{~mm}$ y blanco y negro, durante una reunión de familia, un sábado a la tarde (1987) de Jorge Andrade, que tuvo escasa difusión en la Argentina. El texto retrata de manera minuciosa el Buenos Aires de los años cuarenta, mediante la historia íntima y cotidiana de una familia de la pequeña burguesía urbana. Ese mundo cerrado y casi autárquico, urdido a partir de las rutinas y los eventos familiares, sirve para referirse al significado que tuvo la irrupción del peronismo en la sociedad. La historia está narrada desde el punto de vista de Zeleste, el hijo mayor de la familia. A través de su mirada se entreteje todo un compendio de personajes que introducen más de una línea narrativa. En la base está la conciencia de que todo relato es una construcción. El pasado existe a partir de la reconfiguración de la experiencia. Por lo tanto la narración deberá aceptar todo aquello de arbitrario y de ficticio como parte inevitable de su estructura. Al recordar,

\footnotetext{
Revista Iberoamericana, Vol. LXXVI, Núms. 232-233 Julio-Diciembre 2010, $741-756$
ISSN 2154-4794 (Electrónico)
} 
el personaje principal organiza la experiencia vivida para darle un sentido a su pasado, lo que implica realizar una lectura sobre la historia. La evocación está centrada en el mundo de la familia, cuyo epicentro es la casa. Este espacio, que según Gastón Bachelard, concentra el valor singular de nuestras imágenes de intimidad protegida, no sólo en tanto que recuerdo sino también como ensoñación (Bachelard 33). Una lectura alrededor de este núcleo semántico permite hacer una interpretación sobre el hecho político, a partir de la metáfora de la "invasión” que había sido utilizada en décadas anteriores para codificar el fenómeno del peronismo (Avellaneda, El habla). La casa es el espacio protegido por antonomasia, que en el texto remite a la experiencia del paraíso de la infancia y que se ve subrepticiamente asaltado por la intrusión de elementos destructivos y corruptores. La rememoración nos va a ir llevando por momentos claves de la conciencia de Zeleste, que va a descubrir varias cosas en relación con su vivencia primera de ese núcleo protegido del hogar. Primero, que el mundo no es un orden clausurado y cerrado. Segundo, que los cambios son inherentes a la vida. Tercero, que la exterioridad nos arroja al caos y la ambigüedad, pero también al pluralismo y la riqueza de interpretaciones. Esto es lo que se refiere sobre todo al tema político. En ese sentido es que se va resquebrajando su universo primigenio de certezas, a la vez que se enriquece su percepción y se ensanchan sus límites. La noción del antes/después va a estructurar muchas de las imágenes que transitan la narración, como un indicio no sólo de las mudanzas en objetos y personas, sino también de la manera en las que se recuerda. El tema del peronismo se encuentra inserto en esa cavilación, ya que se lo interpreta a partir de la matriz de lo que significa el paso de la niñez a la adultez, mediatizado por el núcleo semántico de "inconsciencia paradisíaca/conciencia de ser-para-la-muerte”. Desdramatizar el sentido de la muerte supone también quitarle dramatismo a lo que fue el peronismo como experiencia para la pequeña burguesía, tema que había sido muy trabajado por la literatura de los años cincuenta y sesenta.

En segundo lugar tenemos los Cuentos de los años felices (1993) de Osvaldo Soriano. El tema de la infancia en relación con el peronismo aparece en la primera de las tres partes en las que se divide el libro. Son diecisiete textos reunidos bajo el subtítulo "En el nombre del padre”. ${ }^{6}$ El tópico del paraíso perdido de la infancia, señalado por los "años felices", se encuentra tramado a partir de la mencionada estructura temporal del antes/ahora, con una función similar a la que veíamos en Proyección... . Sólo que aquí el tono es más risueño y menos melancólico. De todos modos, está presente la idea de que el sujeto adulto puede recuperar un territorio que le sirve como mapa de su subjetividad mediante ese pasado evocado y que se busca reconstruir. Soriano recurre a un significante tomado del cine para dar título al texto que cierra la serie. Se trata

6 El autor aclara en la introducción que esos textos se publicaron en Página/12 y que fueron pensados como "relatos sobre la infancia" en los que luego la figura del padre fue tomando mayor protagonismo.

$\begin{array}{lllll}\text { Revista Iberoamericana, Vol. LXXVI, Núms. 232-233 Julio-Diciembre 2010, } & \text { 741-756 } \\ \text { ISSN 0034-9631 (Impreso) } & \text { ISSN 2154-4794 (Electrónico) }\end{array}$ 
de "Rosebud", la referencia a la película Citizen Kane (1941) de Orson Welles. En la infancia, materializada por ese trineo, estaría la seña de identidad del individuo que llegó a ser. Por eso se lo recuerda en el momento de la muerte al cerrar un ciclo.

La fragmentación y la digresión sirven para reflejar las dinámicas de la memoria. Aquí también los objetos son los disparadores de la acción de recordar. Y esta actividad está puesta en función de un presente del cual no se habla, pero que se coloca a manera de telón sobre el que se proyecta el pasado. El dispositivo central es la figura del padre que sirve para trazar un antagonismo con visos de rivalidad. A través de estos relatos se cuenta la relación entre el padre y el hijo, caracterizada por un permanente juego de escaramuzas. El vector que los separa es la política que los ha colocado en veredas opuestas: el padre es antiperonista mientras que el hijo vive su infancia durante ese primer peronismo, que para él era como un "reino de duendes protectores" (Soriano 49). La diferencia tiene sus raíces en la distancia generacional. El padre había crecido bajo otro consenso, el de la nación liberal instituida por la Generación del ochenta y el orden conservador. El hijo, en cambio, vive su infancia en un mundo en donde ese consenso se ha resquebrajado. ${ }^{7}$ La fascinación del hijo por el peronismo se debe en gran medida a ese lugar de privilegio patrocinado por el discurso del régimen. Se hace beneficiario de los juguetes que regalaba la Fundación Eva Perón, así como de las políticas peronistas concernientes al deporte. La austeridad del padre no resultaba atractiva a los ojos de aquel niño deslumbrado por los gestos espectaculares de la pareja presidencial. La narración de esos años superpone sobre los recuerdos otros discursos que contribuyeron a alimentar el imaginario de la época, tales como el cine y las historietas. Como se ve en el cuento “Gorilas”, Perón emerge en la fantasía infantil como si fuera un personaje de historieta en franca competencia con el ascetismo y sentido del deber encarnados por el padre. $\mathrm{Al}$ igual que en la novela de Andrade, se repite la simpatía del niño protagonista tanto hacia Perón como hacia Evita, vistos como figuras protectoras.

Al trabajar el tópico del paraíso perdido de la infancia se utiliza como base la dicotomía temporal antes/ahora. Trasladada al momento en el que el sujeto rememora su niñez, el espacio luminoso del ahora peronista corporiza la consagración de los tiempos. El narrador deja constancia de que ese período cristalizó en una base sobre la cual él pudo fundar una subjetividad más allá de los conflictos de la época. En ese pasado, el peronismo había cumplido la función de asegurar el cumplimiento de su deseo. Los juguetes regalados por la Fundación sintetizaban para el niño la felicidad de esos años. Pero también aparecen en los relatos otras obras que representaban logros del régimen peronista, como los trenes nacionalizados y los yacimientos petrolíferos. Todos ellos quedan como testimonios de una época en la que se pudo generalizar la idea de un Estado de Bienestar, que llenaba de orgullo tanto al hijo como al padre.

\footnotetext{
7 Para esta idea del quiebre en el consenso sobre el modo de entender la política, me baso en el análisis que hace Mariano Plotkin en su libro Mañana es San Perón.

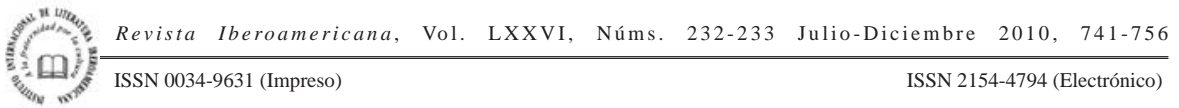


RELATOS DE INFANCIA: DEL OTRO LADO DEL ESPEJO

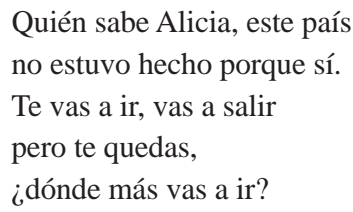

Canción de Alicia, Serú Girán

Existe otra serie en la que se cruzan la temática de la infancia con la del peronismo, pero desde una perspectiva opuesta a la que emergía de los textos anteriores. El espacio de la niñez no es el de la inocencia ni mucho menos el de un paraíso perdido. Se trata de un lugar inquietante, que puede llegar incluso a tener rasgos de infernal. Podría pensarse en ellos como de una torsión en el género del Bildunsgroman, cuyo resultado es un aprendizaje no orientado hacia la integración del sujeto en la comunidad sino hacia una praxis de la supervivencia. El hecho de que el peronismo aparezca tramado en ellas a partir de una genealogía alternativa, de tipo matrilineal, de alguna manera se inserta en una concepción que apunta a una recuperación del Estado de Bienestar. Es decir al aspecto protector y proveedor de esa instancia. No debería llamar la atención que estos textos hayan aparecido a mediados de la década de los noventa, en la corriente de un discurso que patrocinaba el desmantelamiento de ese Estado. La imagen que se propicia es la de una niñez librada a su suerte o francamente desamparada.

La novela El muchacho peronista (1992) de Marcelo Figueras funciona en ese sentido como un ejemplo de la mala educación. La estructura de folletín, episódica y urdida a partir de las aventuras de su joven protagonista, remite a la tradición de la novela picaresca. Una cierta línea narrativa reflexiona sobre el rol de la ficción como generadora de relatos. Esta línea se torna herética al cuestionar al gran relato maestro de la Biblia. Su intención es relativizar todo relato, a la vez que referirse al poder de la literatura para engendrar una realidad con leyes propias. El protagonista es Roberto Hilaire Calabert, un chico de trece años que se escapa de su casa una noche de 1938. Se lanza a la aventura tomando un tren hacia el interior de la provincia de Buenos Aires. A partir del encuentro con el mafioso polaco Tardewski, quien se convertirá en su mentor, va a vivir una seguidilla de aventuras que lo conducirán en un movimiento descendente hacia una experiencia cada vez más pesadillesca. En una de esas vueltas se topará con un todavía ignoto Juan Domingo Perón, al que mata de un tiro. Con ese asesinato tan gratuito como espontáneo Roberto va a dar pie a una reescritura de la historia argentina. Perón muere mucho antes de ser Perón, es decir, el fundador del Partido Justicialista. Recién acababa de llegar de su frustrada gestión en Chile y Roberto se encuentra con él en un prostíbulo de Junín. Muerto Perón, la historia sigue a través de Potota, su primera esposa, cuyo nombre completo era María Aurelia Tizón. A través

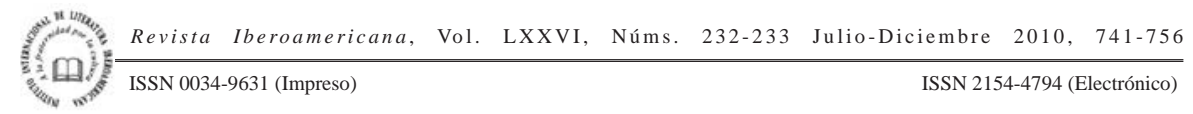


de este episodio se narra en clave novelesca un capítulo de la vida de Perón que no suele ser trabajado por la historiografía. Con el título de "Potota" se incluye un relato que podría ser considerado como la prehistoria del General: su noviazgo y la boda con la que fuera su primera esposa, de la que circula muy poca información. El paralelo trazado mediante esta reescritura de la historia, queda reforzado mediante la línea que da una versión alternativa de la historia bíblica del traidor Judas. La función imaginativa ofrece la posibilidad de abrir otro horizonte.

Luego de matar a Perón, Roberto sigue viaje con su viuda. Entre ambos se establece un vínculo que será codificado como familiar. Potota, que no puede tener hijos (luego morirá de un cáncer de útero), adopta informalmente a Roberto, quien por su parte ya había desarrollado una relación filial con su mentor Tardewski: "Potota me abrazó. Yo lo abrazaba a él. Hicimos una cadena, los tres: la familia perfecta” (Figueras 264). Esta nueva familia surgida de las circunstancias se instaura como línea alternativa a la progenie carnal y legal, por afuera de todas las estructuras societales. Se da como fruto de una elección, aunque en realidad haya sido el resultado de maniobras viciadas por la violencia y la desesperación. Roberto encuentra en Tardewski al padre ausente (su padre había huido hacía muchos años), pero en una relación que es como el reverso de un lazo sano entre padre e hijo. Según la opinión de Andrés Avellaneda, Potota se convierte en una especie de "pre-protoEva", ya que con ella se abre una bifurcación en el relato de la historia argentina: al matar a Perón la historia continúa mediante la vertiente femenina del movimiento (Avellaneda, "Recordando con ira” 134). La ficción permite crear mundos paralelos en los que se hace posible imaginar otras facticidades. En este caso, un nuevo pacto social que prioriza el componente relegado por la tradición patriarcal de la política.

En una entrevista hecha en 1992, Marcelo Figueras aclara por qué eligió el título y qué es lo que lo hizo preferir el singular del "muchacho peronista” al plural inmortalizado por la Marcha Peronista. Se plantea la aventura de su personaje como una utopía individual. Ya no se trata de salvar a la gran masa sino de salvarse a sí mismo. Constata que en su presente las utopías son “casi individuales”. Lo explica desde el ángulo de su oficio, la escritura, diciendo que toda reconstrucción de lo social o de la utopía, pasa por el proyecto personal. Su proyecto es trabajar como escritor y desde ese puesto lo que caracteriza una utopía es la ambigüedad, aceptando "las contradicciones que hay en la vida”. Es una consecuencia del período histórico que le tocó vivir y eso explica por qué encara el gesto arrebatado de matar a Perón en una novela que poco tiene de histórica:

Yo tenía 13 años cuando el golpe de Estado del 76 y crecí sin saber lo que pasaba. No entendía, pero lo que resultaba claro era que tenía miedo y ese miedo me hizo mierda. Entonces todo lo que hice, desde que pude, lleva esa marca a la inversa. Es decir, probarme que no tengo miedo, meterme en berenjenales como matar a Perón o reescribir el Evangelio. (Russo)

\footnotetext{
Revista Iberoamericana, Vol. LXXVI, Núms. 232-233 Julio-Diciembre 2010, $741-756$
ISSN 0034-9631 (Impreso)
} 
Es posible establecer algunos paralelos con otra novela aparecida en 1992, El cadáver imposible de José Pablo Feinmann. En este caso la protagonista es una niña, Ana. El relato se presenta como un texto de ficción redactado por un escritor que pretende hacer una novela o un guión cinematográfico. El texto va mutando a lo largo de la escritura, que adscribe al recurso de verosimilitud clásico de la carta enviada a un editor. Pero es un texto híbrido hasta lo carnavalesco. Para el lector, se va desplegando no sólo la narración de esa historia, sino también el proceso de escritura. Mediante el discurso de este narrador delirante y megalómano van a ser tratadas varias cuestiones. Una de ellas tiene que ver con la manera en que los medios masivos de comunicación se posicionan entre los hechos narrados y sus destinatarios. El intento de recrear narrativamente el género cinematográfico del Gore ${ }^{8}$ apunta a desnaturalizar muchos de los recursos que en la actualidad ya son parte del repertorio de los medios audiovisuales, con sus excesos de violencia, sadismo y grotesco. Además de lo que Feinmann considera la "obscenidad" de esos medios, referida a la intención de mostrarlo todo, de hacer creer la falacia de su rol como meros intermediarios transparentes entre algo que se supone es la realidad y el espectador. En gran medida comparte la atmósfera bizarra e infernal de la novela de Figueras. Además de que ambas tienen en común una reflexión acerca del relato, de su capacidad de fagocitar otros discursos, así como de sus posibilidades creativas.

El cadáver imposible pone en escena la historia de Ana, una chica de catorce años que va a parar a un reformatorio de menores en la provincia de Buenos Aires. Su historia comienza un poco antes, cuando a los nueve años asesina a su madre en un gesto arrebatado y gratuito, porque la descubre teniendo relaciones sexuales con un amante. Esta escena primaria provoca una enorme violencia en la niña, que no logra superar el trauma. Luego de estos hechos preliminares, la acción comienza en el reformatorio del pueblo ficticio de Coronel Andrade con la llegada de una nueva directora. Se trata de una mujer dura, convocada para poner orden en el descalabro del reformatorio de jovencitas. La nueva jefa de celadores se llama Elsa Castelli. Se nos dice que es alta y rubia, y que su rostro "no nos es desconocido" (36). Aunque también se aclara que Elsa es idéntica a la madre de Ana, una serie de evocaciones apuntan a identificarla con la figura de Eva Perón: lleva traje gris y rodete, repite algunas de las frases conocidas de Evita. ${ }^{9}$ Esta construcción que hace el narrador de su personaje Elsa Castelli a partir

8 Gore es un término inglés que quiere decir "sangre". Se refiere a un tipo de cine de películas de terror, caracterizado por la exhibición de lo visceral y la violencia explícita. Su intención es mostrar la vulnerabilidad del cuerpo humano mediante el uso de exceso de sangre y la teatralización de la mutilación. El exceso como recurso puede ser tal que llegue a provocar efectos de comicidad.

9 Esta lectura se encuentra en varios trabajos críticos que estudian las representaciones literarias de la figura de Eva Perón. La primera en mencionarlo es Ana María Amar Sánchez en "Evita: cuerpo político/ imagen pública” (Navarro 54). También lo menciona Susti González en su libro Eva Perón: melodrama, cuerpo y simulacro, en la página 111. Más detallado es el análisis que hace Viviana Plotnik en el capítulo III de su libro Cuerpo femenino, duelo y nación.

\begin{tabular}{lllll} 
Revista Iberoamericana, Vol. LXXVI, Núms. 232-233 & Julio-Diciembre 2010, & 741-756 \\
\hline ISSN 0034-9631 (Impreso) & ISSN 2154-4794 (Electrónico)
\end{tabular} 
de la fisonomía de Eva Perón, es la única mención al peronismo que encontramos en la novela. De hecho, ni siquiera es posible establecer un paralelismo total entre el personaje histórico y el ficticio, cuyo discurso se encuentra atravesado por una serie de contradicciones muy marcadas, a partir del trazo grueso elegido como recurso estilístico para todo el relato. Siguiendo la reflexión que hace Viviana Plotnik, la Eva/Elsa Castelli de la novela de Feinmann está construida a la manera del collage, lo que refuerza su carácter de "artefacto cultural" compuesto de imágenes y proyecciones inconscientes (77-85). Sobre ella se superponen elementos paradójicos, porque si bien por un lado su crueldad arbitraria remite al terror de la dictadura, para Ana encarna la figura del "Hada Buena”. Pero sobre todo es el tópico del cadáver el que remite a Eva Perón. Se toman elementos de la historia mitificada del cadáver embalsamado, que fue tratado discursivamente como si fuera una muñeca. Como consecuencia de los métodos brutales que implementa Castelli para imponer el orden, un grupo de reclusas lleva a cabo una venganza que tiene como resultado el asesinato de Elsa. No sólo la asesinan, sino que la descuartizan y queman sus miembros. Ana llega justo a tiempo para rescatar la cabeza, la única parte del cuerpo que pervive, como en el cuadro de Santoro. Lo que sigue es previsible: Ana continúa la seguidilla de crímenes para vengarse de sus compañeras. Las mata una a una, les corta los miembros, y con ellos rearma el cadáver de su querida Elsa Castelli. El resultado es monstruoso, un engendro imposible de revivir.

El tema del cadáver de Evita se cuela también en el cuento de Rodrigo Fresán, “El único privilegiado”, incluido en el libro Historia argentina (1991). De nuevo el tema pasa por el relato ficcional, su capacidad de imponerse por sobre los otros discursos y de generar realidad. El narrador de este cuento es un personaje que se reconoce como un sujeto narrador de falsedades, un mitómano. La anécdota queda enmarcada por una introducción a cargo de un narratario que se presenta como escritor y usa el artificio de ceder la palabra a su interlocutor. Se nos introduce en un ambiente de clase alta con aires de aristocracia vernácula, en una mansión francesa de diecisiete habitaciones. La evocación retrocede a los cinco años del protagonista, para luego pegar varios saltos que entretejen distintos momentos de la historia individual, de la que se escuchan los ecos de la historia nacional. El relato del niño comienza con la llegada de Mónica, persona de apariencia insignificante, pero con la que empezará a correr el tiempo de la conciencia del personaje principal. Contado mediante eufemismos, se dice que Mónica es hija ilegítima del padre. A la familia no le queda más remedio que aceptarla como “dama de compañía” para el hijo, luego de que la chica quedara huérfana de su madre. En consecuencia, la esposa legal y madre del protagonista, siempre detestará a Mónica. De ahí en más Mónica pasará a ser un objeto dentro de la mansión: "Iba a ser un juguete irrompible. Me la habían regalado y ella aceptó esto con una dignidad que superaba la resistencia de cualquier ingenio mecánico” (Fresán 45). La anécdota en sí ocurre a los once años del protagonista, en un momento de transición signado por el despertar sexual. El niño siente amor y odio mezclados por esa chica que ya tiene dieciséis, de

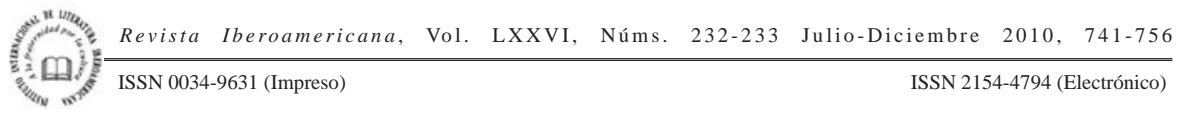


cuya subjetividad no sabemos nada. En un arranque de celos la responsabiliza de haber robado un anillo de la madre, lo que provoca la expulsión de la joven. La escena que tiene lugar luego parece ser más bien un delirio del protagonista, en cuya conciencia se superponen la persona de Mónica con la de Eva Perón, mediante un cruzamiento que es de clase. Al querer violar a Mónica, el protagonista estiliza la situación. Mónica ya había sido rebajada al nivel de juguete, de modo que su conversión en muñeca gigante para uso del señorito era el paso siguiente, casi instantáneo. No sorprende entonces que al adolescente se le aparezca como el cadáver embalsamado, feérico, de Eva Perón:

Yacía sobre la cama. Desnuda y perfecta. Su cuerpo parecía emitir un débil reflejo azulado. Caminé hacia ella como quien camina por el fondo del mar y su propio resplandor la hizo diferente a mis ojos. Su rostro parecía otro sin dejar de ser el mismo. Era el rostro de una santa. (Fresán 47)

Esta superposición, fruto del ensueño, busca luego una explicación racional. El narrador adulto dirá que en ese entonces él tenía nulo contacto con la realidad exterior a su casa, mucho menos con la situación política. Recién después se enteraría por revistas y diarios de la existencia de la "abanderada de los pobres". Podemos imaginar, de todos modos, la intrusión de ese mundo exterior invasivo como el ronronear de las charlas en la casa, de las conversaciones obligadas de una clase social que se sentía amenazada por un nuevo orden. Aquí también se lleva al singular del título una situación que en su origen era comunitaria. Es uno sólo el que puede usufructuar, desde la privatización, aquello que en principio estaba destinado al colectivo.

\section{CONCLUSIÓN}

La lectura que hemos hecho del tema de la infancia apunta a delimitar aquello concerniente a los mitos del peronismo que es reeditado en una determinada coyuntura histórica. En este caso, interesa en concreto analizar la concepción de Estado subyacente a uno de esos mitos, en lo que puede ser considerado un giro inédito, cuyo alcance logra verse mucho tiempo después y más allá de los discursos oficialistas de aquel momento. Las novelas mencionadas se encuentran todas cercanas en el tiempo de su publicación y, en cierto modo, pueden ser identificadas como corpus. Es posible distinguir dos grupos diferenciados, pero no por fuerza antagónicos. La línea de separación pasa por una experiencia codificada como positiva o como negativa. Esto tiene mucho que ver con una cuestión del género textual elegido. El tono en la novela de Andrade, así como en los cuentos de Soriano, ambos más cercanos a una intención descriptiva y, por lo tanto, a un estilo realista, opta por recrear con nostalgia un tiempo pasado. El presente se encuentra sólo sugerido desde la voz que narra. En los otros textos prima una intención satírica o lisa y llanamente grotesca, que los ubica dentro de otra línea.

\footnotetext{
Revista Iberoamericana, Vol. LXXVI, Núms. 232-233 Julio-Diciembre 2010, $741-756$
ISSN 2154-4794 (Electrónico)
} 
Sin embargo la dicotomía antes/ahora está presente en ambos grupos. Aunque en estos textos el pasado no pueda ser significado como un paraíso, sigue siendo una fuente desde la que extraer una clave de interpretación para el presente. Existe en todos el impulso de buscar allí algo que se ha perdido. Lo que permite seguir esta línea interpretativa es la presencia de Eva Perón como cifra de un espacio de protección, lo que hemos mencionado como el "Estado maternal", que es una de sus tantas mutaciones performáticas dentro del espacio de actuación política que le deparó su tiempo. Se da tanto en la figura dulcificada de Potota, como también en la ambigua, por lo agresiva, de Elsa Castelli, o en la sexualizada y "edípica” de Mónica. Son todos aspectos que caben a una visión del rol proveedor del Estado, condicionada por una codificación desde el género sexual. Tanto en la novela de Figueras como en el cuento de Fresán, se denota el individualismo preconizado por el discurso liberal de los noventa. La brutalidad de sus textos emerge como reacción a un contexto que no ofrece opciones colectivas de redención. La tarea del escritor parece limitada a las aventuras individuales, orientada sobre todo a abrir el lenguaje y a multiplicar sus posibilidades sémicas. En el caso de la novela de Feinmann, se respira la indignación frente a la imposibilidad de dar nueva vida a todo aquello significado por el Estado de Bienestar. Su novela se confronta con la cuestión de los medios de comunicación, maniatados por los imperativos del mercado. Llamativo es que a la hora de buscar los rastros de ese Estado identificado con una era de modernización y progreso, los imaginarios de los noventa recurran al peronismo del bienestar corporizado por quien se presentaba como su cara más visible, Eva Perón. Volviendo al punto de partida, el cuadro "Hallazgo", sólo subsisten fragmentos, como esa cabeza abandonada en el desierto. Son los pedazos desparramados en los textos, trazos que hablan de la necesidad de una reconstrucción, de una actitud arqueológica. Queda claro que no es uniendo los pedazos que se va a reconstruir el cuerpo. Eso ya es parte de un cadáver imposible. Pero la memoria de un tiempo pasado que fue feliz sigue presente en cierto imaginario, que añora recuperar un sentido colectivo de lo social y una utopía modernizadora basada en el bienestar.

\section{BiBLIOGRAFÍA}

Andrade, Jorge. Proyección en 8 mm y blanco y negro, durante una reunión de familia, un sábado a la tarde. Barcelona: Muchnik, 1987.

Avellaneda, Andrés. El habla de la ideología. Buenos Aires: Sudamericana, 1983.

“Evita: cuerpo y cadáver de la literatura”. Evita. Mitos y representaciones. Marysa Navarro, comp. Buenos Aires: FCE, 2002. 101-141.

"Recordando con ira: Estrategias ideológicas y ficcionales argentinas a fin de siglo”. Revista Iberoamericana LXIX/202 (2003): 119-135.

Bachelard, Gastón. La poética del espacio. 1957. Buenos Aires: FCE, 1990.

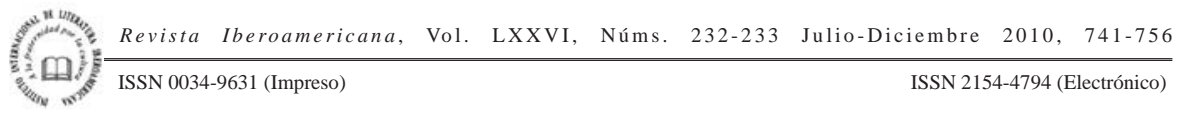


Berrotarán, Patricia, Aníbal Jáuregui y Marcelo Rougier, editores. Sueños de bienestar en la Nueva Argentina. Estado y políticas públicas durante el peronismo. 19461955. Buenos Aires: Imago Mundi, 2004.

Butler, Judith. El género en disputa. El feminismo y la subversión de la identidad. 1990. Barcelona: Paidós, 2007.

Feinmann, José Pablo. El cadáver imposible. Buenos Aires: Norma, 1992.

Figueras, Marcelo. El muchacho peronista. Buenos Aires: Planeta, 1992.

Fresán, Rodrigo. Historia argentina. Buenos Aires: Planeta, 1991.

Gené, Marcela. Un mundo feliz. Imágenes de los trabajadores en el primer peronismo 1946-1955. Buenos Aires: FCE, 2005.

Goldar, Ernesto. "La literatura peronista”. El peronismo. AAVV. Buenos Aires: Cepes, 1973. 139-186.

Heim, Perla, ilustradora. Hada Buena Argentina. Buenos Aires: Secretaría de Información del Ministerio del Interior, ca. 1950.

Mayer, Marcos, compilador. El peronismo. Historias de una pasión argentina. Buenos Aires: Ediciones Instituto de Fondos Cooperativos, 1994.

Moraña, Mabel y María Rosa Olivera-Williams, editoras. El salto de Minerva. Intelectuales, género y Estado en América Latina. Madrid/Frankfurt aM: Iberoamericana/Vervuert, 2005.

Ortiga Caicedo, Alicia. "Los hechizos de Eva Perón: del cuerpo embalsamado al cuerpo nómada”. El salto de Minerva. Moraña, Mabel y María Rosa Olivera-Williams, editoras. Madrid/Frankfurt aM: Iberoamericana/Vervuert, 2005. 173-187.

Plotkin, Mariano. Mañana es San Perón. 1994. Caseros: Eduntref, 2007.

Plotnik, Viviana. Cuerpo femenino, duelo y nación. Un estudio sobre Eva Perón como personaje literario. Buenos Aires: Corregidor, 2003.

Rein, Raaan. Peronismo, populismo y política. Argentina 1943-1955. Buenos Aires: Fundación Editorial de Belgrano, 1998.

Rosano, Susana. "El paraíso perdido del peronismo (Algunos apuntes para pensar la obra de Daniel Santoro)". Políticas del sentimiento. El peronismo y la construcción de la Argentina moderna. Soria, Claudia, Paola Cortés Rocca y Eduardo Dieleke, compiladores. (Cortesía de la autora, en prensa en la Editorial Edhasa).

Rosano, Susana. "Reina, santa, fantasma: la representación del cuerpo de Eva Perón”. El salto de Minerva. Moraña, Mabel y María Rosa Olivera-Williams, editoras. Madrid/Frankfurt aM: Iberoamericana/Vervuert, 2005. 189-204.

Russo, Miguel. "Nuestra utopía es sacar un libro por año. Entrevista a Rodrigo Fresán y Marcelo Figueras”. La Maga 9. 11 de marzo de 1992.

Santoro, Daniel. Manual del niño peronista. Buenos Aires: La Marca, 2002.

Soria, Claudia. “La voz de Eva Perón: ¿Qué dice una mujer cuando habla?”. Delirios de grandeza. Pons, María Cristina y Claudia Soria, compiladoras. Rosario: Beatriz Viterbo, 2005. 145-160.

Revista Iberoamericana, Vol. LXXVI, Núms. 232-233 Julio-Diciembre 2010, $741-756$
ISSN 2154-4794 (Electrónico) 
Soriano, Osvaldo. Cuentos de los años felices. Buenos Aires: Sudamericana, 1993. Viñas, David, director; Guillermo Korn, compilador. El peronismo clásico (1945-1955).

Descamisados, Contreras y gorilas. Literatura argentina del siglo XX. Buenos Aires: Paradiso/Fundación Crónica General, 2007.

Wainerman, Catalina y Mariana Heredia ¿Mamá amasa la masa? Cien años en los libros de lectura de la escuela primaria. Buenos Aires: Editorial Belgrano, 1999.

Revista Iberoamericana, Vol. LXXVI, Núms. 232-233 Julio-Diciembre 2010, $741-756$
ISSN 2154-4794 (Electrónico) 